\section{H. Macit Selekler
Sezer Komsuoğlu \\ H. Macit Selekler
Sezer Komsuoğlu}

Received: 16 December 2003

Accepted in revised form: 31 August 2004

This study was not funded by any company or institution.

H.M. Selekler $(\bowtie) \cdot S$. Komsuoğlu Department of Neurology,

Kocaeli University Medical Faculty,

Dekanlik Binasi,

Sopali Çiftliği, Derince 41900,

Kocaelı, Turkey

e-mail: macitselekler@tnn.net

Tel.: +90-532-4748025

\title{
Unconventional treatment methods in Turkish migraine sufferers
}

\begin{abstract}
We wanted to document Turkish migraine sufferers' unconventional therapy methods learnt from their social environment and discuss the historical background and possible action mechanisms of these methods. Unconventional therapy methods were documented among 482 migraine patients who consulted Kocaeli University Medical Faculty, Neurology Department's "Headache outpatient clinic". Among 482 migraine patients, 154 sufferers $(31.9 \%)$ had been using unconventional therapy methods. Among these patients, the most frequently used methods were using a head bandage (25.9\%), applying cold water to head
\end{abstract}

(23.4\%), massage (16.2\%), applying ice to head $(15.6 \%)$, taking a hot or warm bath (10.4\%) and inserting sliced vegetables under the head bandage (7.8\%). However, our data may not represent all Turkish migraine sufferers as our sample was drawn from a clinical sample living in the most western part of Anatolia, the city of Kocaeli bordering Istanbul. Determining the efficacy of these methods was beyond our aim; however, a more systematic study about the given case may be even more interesting.

Key words Migraine $\cdot$ Head bandage $\cdot$ Cold water $\cdot$ Massage $\cdot$ Ice $\cdot$ Bath

\section{Introduction}

Various types of headache remedies have been tried by headache sufferers for thousands of years and some of these methods are still in use. Modern science cannot discard these methods and they are also found to be worth discussing in chapters of headache textbooks.

As migraine sufferers who consult our outpatient headache clinic frequently report various unconventional therapy methods for the attacks, we thought that these methods would be worth taking into consideration. The rate of applying unconventional methods of migraine sufferers, the historical background of these therapies and their possible action mechanisms were aimed to be discussed in this study.

\section{Materials and methods}

Four hundred and eighty-two migraine patients who consulted Kocaeli University, Faculty of Medicine, Neurology Department's "Headache outpatient clinic" between May 2001 and March 2003 
were evaluated for the study. All patients' diagnoses were made according to International Headache Society's "migraine" criteria [1] on a one-digit level with a semi-structured interview.

A standard form questioning headache duration, localisation, quality, severity, aggravation with physical activity and accompanying symptoms such as photophobia, phonophobia, nausea and vomiting and relieving factors of their headache was filled in for each patient. All patients were interviewed by H.M.S. and were asked two complimentary questions about relieving factors: (1) What eases your migraine attacks? (2) What do you generally do during your migraine attacks in order to relieve it?

In order to not influence patients' replies, a suggestion was not made, nor was an example given to the patients during the interview; only patients' own reports were noted. Patients who applied unconventional therapy methods such as applying pressure, hot/cold to the head and massage during the migraine attacks were chosen for the study. Patients' age, gender, occupation and type of unconventional therapy used were documented.

\section{Results}

Unconventional therapy methods were determined in 154 of $(31.95 \%)$ among 482 migraine sufferers. Of these patients, 19 were males and 135 were females. Mean age was $37.81 \pm 13.12$ (range $=14-78$ years). Eighty patients were housewives, 31 were government officers, 22 were students, 11 were retired and 10 were self-employed. A second method was determined in 29 patients, and a third method was determined in 2 patients. All of the patients reported that they applied these methods as adjuncts to medication and/or as adjuncts to non-medicinal methods such as resting, sleeping.

Fifty-two patients reported that they wrapped their heads with a bandage in order to ease their headache.
Among these 52 patients, 12 reported that they put slices of potato $(n=7)$, lemon $(n=3)$, cucumber $(n=1)$ and radish $(n=1)$ under the bandage, on the bilateral temporal regions and frontal area.

Applying ice to the head and washing the head with cold water was reported by 24 and 36 patients, respectively, whereas applying heat to the head was reported by 9 patients.

Taking a bath or shower with warm water was reported by 15 patients, while just one patient reported taking a hot shower in order to relieve his pain.

Beneficial effects of massage to the head and neck were reported by 31 patients. Six of these patients reported that they used lemon cologne during the massage.

Seven patients reported that they drank tea and 2 drank coffee for pain relief. Five reported that they drank freshly squeezed lemon juice, 2 drank milk and 1 ate yoghurt for relief.

Percentages of applied unconventional methods for headache relief are given in Table 1 , both for all migraine patients who consulted us, and for migraine sufferers who use these methods.

\section{Discussion}

Pressure applied to the head during headache is an ancient remedy that has only recently been evaluated systematically [2]. In an Egyptian papyrus which is 3000 years old, this treatment method of migraine was interpreted as a clay crocodile holding grain in its mouth being firmly bound to the head $[3,4]$. In the 13 th century in Italy a widely used treatment for headache was applying a poultice soaked in

Table 1 Unconventional remedies in Turkish migraine sufferers

Unconventional remedies
Percentage in all migraine sufferers in the group $(n=482)(\%)$
Percentage in migraine sufferers adopting unconventional remedies $(\mathrm{n}=154)(\%)$

Head bandage $(n=40)$

Head bandage and inserting sliced vegetables $(n=12)$

Applying cold water $(\mathrm{n}=36)$

Applying ice $(\mathrm{n}=24)$

Massage $(n=25)$

Massage with cologne $(n=6)$

Taking warm or hot bath $(\mathrm{n}=16)$

Applying heat $(n=9)$

Drinking coffee or tea $(n=9)$ 
opium and vinegar to the head [5]. In "Othello", Shakespeare also discusses a headache treatment provided by binding a handkerchief to the head [3, 4]. In the 16 th century, Indians of North America, used to apply crushed leaves and bark of America birch and Norway spruce to the temple for pain relief [6]. Edmeads [5] does not credit that any material applied to head is likely to attain enough serum concentration to exert analgesic effect but points to the possibility of the compressive effect of the applied material in relieving the pain. Presumably, pressure works in vascular headache either by compressing painfully distended extracranial vessels or through the effects of counter-irritation [2].

In our group, 40 patients reported that they used a head bandage to ease their headaches and 12 patients put sliced potato, lemon, cucumber or radish under the bandage.

Vijayan [7] observed that a simple band wrapping around the head did not provide enough pressure over areas of maximum pain whereas it applied too much pressure in areas without pain. He found an additional method of applying localised pressure; a rubber disc $1 \mathrm{~cm}$ in thickness and $3 \mathrm{~cm}$ in diameter inserted under the elastic band. In his study, 23 migraine patients gained relief in $87 \%$ of their aggregate headaches to varying degrees. The traditional method that is carried out by our patients, like putting sliced potato, lemon, cucumber or radish under the band, probably provides the same pressure effect with Vijayan's elastic fastener, rather than any analgesic effect of the absorption by the skin.

Application of cold to the head is another historic method of treating migraine headaches [2]. Apart from the pressure effect, binding clay crocodile to the head may have a cooling effect on the scalp. Beneficial effects of cold application have been suggested by several studies [8-10]. Although it has been proposed that cold constricts blood vessels, numbs pain fibres and decreases muscle spasm [2], Lance [8] is uncertain whether the effect of cold is exerted by inducing vasoconstriction or by simple counter-irritation. Twenty-five of our patients seek remedy by applying ice to their head while another 36 patients hold their heads under the running tap's/shower's water which is, as supposed, colder than body temperature.

Application of heat to the head during headache also has a historical background. Albucasis (936-1013 A.D.) recommended the laying of a red-hot poker (application of hot iron) on the temple to relieve headache [3, 6]. The Delaware would lay a piece of white walnut bark on the temples; when moistened, the bark became exothermic and produced local heat which would ease the pain [6]. Eight of our patients reported that application of heat to the head also provided relief from headache. It has been suggested that superficial heat raises the skin and subcutaneous temperature to a depth of $2-3 \mathrm{~cm}$; the related increase in super- ficial blood flow produces cooling in underlying joints and may contribute to pain relief [11].

Beneficial effects of hot and warm baths have also been mentioned in the literature [7, 12]. Galen (A.D. 131-201) attributed hemicrania to "ascent of vapors, either... too hot or too cold" [3]. In Hebrew sages, quoting Galen, Maimonides states: "if head-illnesses occur due to a faulty warm constitution, it is proper to bath often in comfortably-warm sweet water, because this dissolves the sharp vapors that arise in the head and improves the body disposition to a more favorable one" [13]. Sixteen of our patients reported that taking a shower with warm water also provided relief from the headache.

Massage is a traditional therapy that has been widely prescribed in diverse cultures for centuries [11]. In Hebrew sages, again quoted from Galen: "if the headache is strongly localised, it is most appropriate to massage in the summertime with oil of roses which is prepared in omphacite oil". The Jerusalem Talmud has at least two references to headache. The first is a remedy to treat headache: rub the head with wine, vinegar or oil [12]. Although its precise mechanism of action has not been defined, massage is known to relieve spasm and to decrease pain, perhaps through spindle receptor stimulation and reflex muscle relaxation. An increase in plasma $\beta$-endorphins has been demonstrated after connective tissue massage [11]. Headache relief with massage was reported by 28 of our patients.

Six of our patients reported that cologne was used during the massage. Cologne, which contains $80 \%$ alcohol, probably creates a voltaic current like menthol. Osier's explanation (1949) about the effect of menthol was: "menthol applied externally produces a feeling of coldness by stimulation of the nerve endings associated with the sensation of cold. There follows a mild degree of anaesthesia due to paralysis of all sensory nerve endings. On this account, menthol is rubbed onto the skin to relieve frontal headache" [6].

Several headache remedies contain caffeine and the drug is believed to reverse the painful cerebral vasodilatation associated with vascular headaches. A majority of people in all age groups ingest large quantities of caffeine; adults in the form of coffee and tea and children through coke and chocolate. A wide variety of physiological changes have been reported following caffeine administration, some of which are known to manifest tolerance development [14]. Nine of our patients reported that they drank coffee or tea in order to abort their attacks. These patients' headaches may be due to caffeine withdrawal or they may drink coffee/tea in order to abort their attacks with caffeine rather than using an over-the-counter analgesic containing caffeine.

Blau [15] suggested that eating could provide some improvement of symptoms during the headache phase of 
attacks. He recommends early medication with warm water to help deglutition and perhaps absorption during the attacks. Elizabeth Garrett Anderson, in her thesis "sur la migraine" (1870), mentioned that a large quantity of very hot tea had been recommended for migraine headaches. She explained the effect of "a large quantity of very hot tea" as having both an emetic and a purgative action, and also a sedative action of the heat on gastric and duodenal nerves. According to Anderson, its remedial action was largely due to the raised temperature [16]. Probably drinking coffee/tea during the attacks has a double effect for migraine attacks.

It has been reported that citrus fruits might precipitate migraine attacks [17], so it seems bizarre to drink lemon juice during the attacks. Drinking milk and eating yoghurt, both of which contain high calcium, is also a matter of question.

To sum up, applying cold material to the head (ice or cold water), using a head bandage (with or without inserted sliced vegetables) and massage (with or without cologne) were found to be the most common unconventional therapy methods for migraine headache in our group.

However, there are some limitations to our study. Our data may not represent all Turkish migraine sufferers because the sample was restricted to a certain geographical area, the city of Kocaeli bordering Istanbul. The sample is further restricted to headache sufferers seeking medical care at a highly specialised treatment centre, a university hospital's headache outpatient clinic. With fear of obtaining false-positive responses, we took great care. This may have resulted in an underestimation of the frequency of usage data as the patients might not have felt free during the interview in such a setting and might not have thought it appropriate to mention unconventional treatment methods without some prompt to do so.

In this study, we aimed to document the frequency of unconventional treatment methods in our sample. This article does not include any data about the effectiveness of these methods. Determining the efficacy of these methods may be even more interesting with further systematic studies.

\section{References}

1. - (1988) Classification and diagnostic criteria for headache disorders, cranial neuralgias and facial pain. Headache Classification Committee of the International Headache Society. Cephalalgia 8[Suppl 7]:1-96

2. Edmeads JG (2000) Unconventional treatments for migraine. In: Olesen J, Tfelt-Hansen P, Welch KMA (eds) The headaches, 2nd edn. Lippincott Williams \& Wilkins, Philadelphia, pp 379-383

3. Lance JW, Goadsby (1998) The history of headache. In: Lance JW, Goadsby PJ (eds) Mechanism and management of headache, 6th edn. ButterworthHeinemann, Oxford, pp 1-8

4. Silberstein SD, Lipton RB, Goadsby PJ (1998) Historical introduction. In: Silberstein SD, Lipton RB, Goadsby PJ (eds) Headache in clinical practice. Isis Medical Media, Oxford, pp 1-8

5. Edmeads J (1991) Bringing treatment to a head. Headache 31:695
6. Edmeads J (1988) Treating the head in headache. Headache 28:496-497

7. Vijayan N (1993) Head band for migraine headache relief. Headache 33:40-42

8. Lance JW (1988) The controlled application of cold and heat by a new device (Migra-lief Apparatus) in the treatment of headache. Headache 28:458-461

9. Robbins LD (1989) Cryotherapy for headache. Headache 29:598-600

10. Shetfell F, Rapoport A, Kudrow L (1989) Efficacy of symptomatic treatment of tension and migraine headaches with the suboccipital ice pillow. Headache 29:327 (abstract)

11. Carlsson JY, Jensen R (2000) Physiotherapy of tension-type headache. In: Olesen J, Tfelt-Hansen P, Welch KMA (eds) The headaches, 2nd edn. Lippincott Williams \& Wilkins, Philadelphia, pp 651-656
12. Cohen MJ (1978) Psychophysiological studies of headache: Is there similarity between migraine and muscle contraction headaches? Headache 18:189-196

13. Rosner F (1993) Headache in the writings of Moses Maimonides and other Hebrew sages. Headache 33:315-319

14. Mathew RJ, Wilson HW (1985) Caffeine consumption, withdrawal and cerebral blood flow. Headache 25:305-309

15. Blau JN (1993) What some patients can eat during migraine attacks: therapeutic and conceptual implications. Cephalalgia 13:293-295

16. Wilkinson M, Isler H (1999) The pioneer woman's view of migraine: Elizabeth Garret Anderson's thesis "Sur la Migraine". Cephalalgia 19:3-15

17. Silberstein SD, Lipton RB, Goadsby PJ (1998) Pathophysiology and epidemiology of headache. In: Silberstein SD, Lipton RB, Goadsby PJ (eds) Headache in clinical practice. Isis Medical Media, Oxford, pp 11-18 